\title{
Kinetics and Mechanism of Oxidation of some $\alpha$ - Hydroxy Acids by Tripropylammonium Fluorochromate in Aqueous Acetic Acid Medium
}

\author{
S. SHANTHI ${ }^{1}$ and S. SHEIK MANSOOR ${ }^{2 *}$ \\ ${ }^{1}$ Research and Development Centre, Bharathiar University, \\ Coimbatore-641046, Tamil Nadu, India \\ ${ }^{2}$ Department of Chemistry, C. Abdul Hakeem College, \\ Melvisharam-632 509, Tamil Nadu, India \\ smansoors2000@yahoo.co.in
}

Received 19 October 2014 / Accepted 8 November 2014

\begin{abstract}
The oxidation of some $\alpha$-hydroxy acids like glycolic, lactic and mandelic acids by tripropylammonium fluorochromate (TriPAFC) have been studied in aqueous acetic acid medium. The oxidation leads to the formation of the corresponding oxo acids. The reaction is first order with respect to TriPAFC, hydroxy acids and $\left[\mathrm{H}^{+}\right]$and the reaction is catalyzed by hydrogen ions. The reaction has been studied in different percentage of acetic acid-water mixture. A suitable mechanism has been proposed.
\end{abstract}

Keywords: Tripropylammonium fluorochromate, Hydroxy acids, Kinetics, Oxidation

\section{Introduction}

Chromium(VI) is established as a versatile oxidant for many types of substrates varying from metal ions to naturally occurring organic compounds ${ }^{1}$. $\mathrm{Cr}(\mathrm{VI})$ as chromate or dichromate is highly soluble in water and is reported to be highly toxic ${ }^{2}$. Hence, there is continued interest in the development of new $\mathrm{Cr}(\mathrm{VI})$ reagents for the effective and selective oxidation of organic substrates, in particular alcohols, under mild conditions. Therefore, the search for new oxidizing agents is of interest to synthetic organic chemists.

In recent years, some new $\mathrm{Cr}(\mathrm{VI})$ based reagents like tetraethyl ammonium bromochromate $^{3}$, benzimidazolium fluorochromate ${ }^{4}$, triethylammonium chlorochromate ${ }^{5}$, imidazolium fluorochromate ${ }^{6}$, tetrahexylammonium fluorochromate ${ }^{7}$ and tributylammonium chlorochromate ${ }^{8}$ were proposed.

Tripropylammonium fluorochromate ${ }^{9,10}$ is also one such oxidant developed recently. It is a more efficient and stronger oxidizing agent. This new compound is more efficient for quantitative oxidation of several organic substrates and has certain advantages over similar oxidizing agents in terms of the amount of oxidant and solvent required, short reaction times and high yields. In this paper, we describe the kinetics and mechanism of the oxidation of glycolic, lactic and mandelic acids by TriPAFC in aqueous acetic acid medium. 
The kinetics and mechanism of oxidation of hydroxy acids by various oxidants have been reported ${ }^{11-19}$. However, no detailed kinetic study of oxidation of hydroxy acids by TriPAFC, a $\mathrm{Cr}(\mathrm{VI})$ reagent has so far been attempted. This prompted us to undertake the present investigation. The present work reports the kinetics of oxidation of $\alpha$-hydroxy acids by TriPAFC and evaluates the reaction constants. Mechanistic aspects are also discussed.

\section{Experimental}

Tripropylamine and chromium trioxide were obtained from Fluka (Buchs, Switzerland). The hydroxy acids used were glycolic acid (GA), lactic acid (LA) and mandelic acid (MA). Acetic acid was purified by standard method and the fraction distilling at $118{ }^{\circ} \mathrm{C}$ was collected.

\section{Preparation of tripropylammonium fluorochromate}

Tripropylammonium fluorochromate has been prepared from tripropylamine, $40 \%$ hydrofluoric acid and chromium trioxide as reported in the literature ${ }^{10}$.

\section{Kinetic measurements}

The pseudo - first-order conditions were attained by maintaining a large excess ( $\mathrm{x} 15$ or more) of hydroxy acids over TriPAFC. The solvent was $50 \%$ acetic acid $-50 \%$ water $(\mathrm{v} / \mathrm{v})$, unless specified otherwise. The reactions were followed, at constant temperatures $( \pm 0.01 \mathrm{~K})$, by monitoring the decrease in [TriPAFC] spectrophotometrically at $359 \mathrm{~nm}$ using UV-Vis spectrophotometer, Shimadzu UV-1800 model. The pseudo-first-order rate constant $\mathrm{k}_{\text {obs }}$, was evaluated from the linear $(r=0.990$ to 0.999$)$ plots of $\log$ [TriPAFC] against time for up to $80 \%$ reaction. The second order rate constant $k_{2}$, was obtained from the relation $k_{2}=k_{o b s} /$ [HA].

\section{Data analysis}

Correlation analysis was carried out using Microcal origin (version 6) computer software. The goodness of the fit was discussed using the correlation coefficient ( $\mathrm{r}$ in the case of simple linear regression and $\mathrm{R}$ in the case of multiple linear regressions) and standard deviation (SD)

\section{Product analysis}

Product analysis was carried out under kinetic conditions i.e., with excess of the reductant over TriPAFC. In a typical experiment, mandelic acid (15.2 g, $0.1 \mathrm{~mol})$, perchloric acid $(0.24$ $\mathrm{mol})$ and TriPAFC (0.012 mol) were dissolved in acetic acid - water mixture (50\%- $50 \%)$ and the solution was allows to stand in the dark for about $24 \mathrm{~h}$ to ensure completion of the reaction. The residue was treated with an excess $(200 \mathrm{~mL})$ of a saturated solution of 2,4dinitro phenylhydrazine in $1 \mathrm{~mol} \mathrm{dm}^{-3} \mathrm{HCl}$ and kept overnight in a refrigerator. The precipitated 2,4-dinitro phenyl hydrozone (DNP) was filtered off, dried and recrystallised from ethanol. The product was identical ( $\mathrm{mp}$ and mixed $\mathrm{mp}$ ) to an authentic sample of the DNP of phenyl glyoxylic acid.

\section{Stoichiometric studies}

The stoichiometric studies for the oxidation of hydroxy acids by TriPAFC were carried out with oxidant in excess. The solvent composition $50 \%$ acetic acid $-50 \%$ water $(\mathrm{v} / \mathrm{v})$ and $\left[\mathrm{H}^{+}\right]$ were maintained as in the corresponding rate measurements. The temperature was maintained at $303 \mathrm{~K}$. The hydroxy acids and TriPAFC were mixed in the ratio 1:4, 1:5, 1:6 and were allowed to react for $24 \mathrm{~h}$ at $303 \mathrm{~K}$. The concentration of unreacted TriPAFC was determined. $\Delta[$ TriPAFC $]$ was calculated. The stoichiometry was calculated from the ratio between [HA] and [TriPAFC]. 
Stoichiometric analysis showed that the following overall reaction.

$$
\mathrm{RCH}(\mathrm{OH}) \mathrm{COOH}+\mathrm{O}_{2} \mathrm{CrFO}^{-} \mathrm{NH}^{+}\left(\mathrm{C}_{3} \mathrm{H}_{7}\right)_{3} \rightarrow \mathrm{RCOCOOH}+\mathrm{H}_{2} \mathrm{O}+\mathrm{OCrFO}^{-} \mathrm{NH}^{+}\left(\mathrm{C}_{3} \mathrm{H}_{7}\right)_{3}
$$

\section{Results and Discussion}

The oxidation of some $\alpha$-hydroxy acids like glycolic, lactic and mandelic acids by TriPAFC have been conducted in 50\% acetic acid and 50\% water medium at $303 \mathrm{~K}$, under pseudo first order conditions and the result obtained were discussed in the following paragraphs.

\section{Effect of varying TriPAFC concentration}

The concentration of TriPAFC was varied in the range of $0.6 \times 10^{-3}$ to $3.0 \times 10^{-3} \mathrm{~mol} \mathrm{dm}^{-1}$ at constant $[\mathrm{HA}],\left[\mathrm{H}^{+}\right]$at $303 \mathrm{~K}$ and the rates were measured (Table 1). The near constancy in the value of $k_{o b s}$ irrespective of the concentration confirms the first order dependence on TriPAFC.

\section{Effect of varying hydroxy acids concentration}

The concentration of the substrates GA, LA, MA were varied in the range of $1.0 \times 10^{-2}$ to $3.0 \times 10^{-2} \mathrm{~mol} \mathrm{dm}^{-1}$ at $303 \mathrm{~K}$ and keeping all other reactant concentrations as constant and the rates were measured (Table 1). The rate of oxidation increased progressively on increasing the concentration of hydroxy acids. The plot of $\log k_{\mathrm{obs}}$ versus $\log$ [HA] gave the slope of $1.01,1.08$ and 1.03 respectively for GA, LA and MA respectively (Figure 1). Under pseudofirst-order conditions, the plot of of $k_{\mathrm{obs}}$ versus [HA] is linear passing through origin. These results confirm the first-order nature of the reaction with respect to [HA].

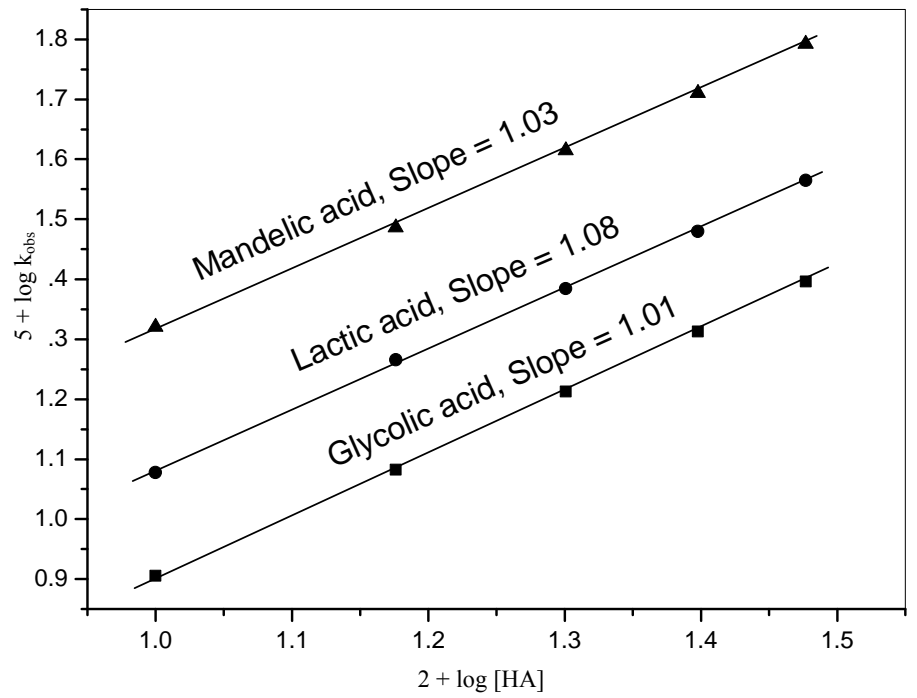

Figure 1. Order plot of HA for the oxidation of hydroxy acids by TriPAFC

\section{Effect of varying perchloric acid concentration}

Perchloric acid has been used as a source of $\mathrm{H}^{+}$in reaction medium. The concentration of $\mathrm{H}^{+}$ was varied in the range 0.12 to $0.36 \mathrm{~mol} \mathrm{dm}^{-1}$ keeping all other reactant concentration as constant at $303 \mathrm{~K}$ and the rates were measured (Table 1). The acid catalysed nature of this oxidation is confirmed by an increase in the rate on the addition of $\mathrm{H}^{+}$. The plot of $\log k_{\mathrm{obs}}$ versus $\log \left[\mathrm{H}^{+}\right]$is a straight line with the slope of $1.04,1.07$ and 1.09 respectively for GA, 
LA and MA respectively. Therefore, order with respect to $\mathrm{H}^{+}$is one for GA, LA and MA respectively. TriPAFC may become protonated in the presence of acid and the protonated TriPAFC may function as an effective oxidant.

\section{Effect of acrylonitrile and $\mathrm{MnSO}_{4}$}

The reaction did not promote polymerization of acrylonitrile indicating the absence of free radicals (Table 1). However, the addition of $\mathrm{Mn}(\mathrm{II})(0.003 \mathrm{~mol} \mathrm{dm} 3)$, in the form of $\mathrm{MnSO}_{4}$ retards the rate of oxidation. This indicates the involvement of $\mathrm{Cr}(\mathrm{IV})$ intermediate in the oxidation of hydroxy acids by $\mathrm{Cr}(\mathrm{VI})$ reagent and confirms the two electron transfer process in the reaction. $\mathrm{Mn}$ (II) ion reduces $\mathrm{Cr}$ (IV) formed to $\mathrm{Cr}$ (III). In the absence of $\mathrm{Mn}$ (II) ion, formed $\mathrm{Cr}(\mathrm{IV})$ reduces $\mathrm{Cr}(\mathrm{VI})$ to $\mathrm{Cr}(\mathrm{V})$ and the oxidation of hydroxy acids by $\mathrm{Cr}(\mathrm{V})$ is fast $t^{20}$. The decrease in the rate of $\mathrm{Cr}(\mathrm{VI})$ reduction on the addition of $\mathrm{Mn}(\mathrm{II})$ has been attributed to the removal of $\mathrm{Cr}(\mathrm{IV})$ by reaction ${ }^{21}$ with $\mathrm{Mn}(\mathrm{II})$.

\section{Effect of acidity}

The reaction is catalyzed by hydrogen ions (Table 1). The acid-catalysis may well be attributed to a protonation of TriPAFC to give a stronger oxidant and electrophile.

$$
\mathrm{O}_{2} \mathrm{CrFO}^{-} \mathrm{NH}^{+}\left(\mathrm{C}_{3} \mathrm{H}_{7}\right)_{3}+\mathrm{H}^{+} \rightleftharpoons(\mathrm{OH}) \mathrm{OCrFO}^{-} \mathrm{NH}^{+}\left(\mathrm{C}_{3} \mathrm{H}_{7}\right)_{3}
$$

The formation of a protonated $\mathrm{Cr}(\mathrm{VI})$ species has earlier been postulated in the reactions of structurally similar $\mathrm{PCC}^{22}$ and $\mathrm{PFC}^{23}$.

Table 1. Effect of variation of $[\mathrm{HA}]$, $[$ TriPAFC $]$ and $\left[\mathrm{H}^{+}\right]$on the rate of the reaction at $303 \mathrm{~K}^{\mathrm{a}, \mathrm{b}}$

\begin{tabular}{cccccc}
\hline $\begin{array}{c}10^{3}[\text { TriPAFC }], \\
\text { mol dm }^{-3}\end{array}$ & $\begin{array}{c}10^{2}[\mathrm{HA}], \\
\mathrm{mol} \mathrm{dm}^{-3}\end{array}$ & $\begin{array}{c}{\left[\mathrm{H}^{+}\right], \mathrm{mol}} \\
\mathrm{dm}^{-3}\end{array}$ & $\mathrm{GA}$ & $\mathrm{LA}$ & $\mathrm{MA}$ \\
\cline { 4 - 6 } & 2.0 & 0.24 & 16.18 & 24.28 & 41.12 \\
1.2 & 2.0 & 0.24 & 16.32 & 24.22 & 41.18 \\
1.8 & 2.0 & 0.24 & 16.22 & 24.10 & 41.28 \\
2.4 & 2.0 & 0.24 & 16.42 & 24.18 & 41.30 \\
3.0 & 2.0 & 0.24 & 16.30 & 24.30 & 41.20 \\
1.2 & 1.0 & 0.24 & 8.04 & 11.96 & 20.42 \\
1.2 & 1.5 & 0.24 & 12.56 & 18.44 & 30.64 \\
1.2 & 2.5 & 0.24 & 26.26 & 30.18 & 51.30 \\
1.2 & 3.0 & 0.24 & 24.88 & 36.72 & 62.00 \\
1.2 & 2.0 & 0.12 & 8.22 & 12.06 & 20.66 \\
1.2 & 2.0 & 0.18 & 12.20 & 18.30 & 30.76 \\
1.2 & 2.0 & 0.30 & 20.16 & 30.32 & 51.42 \\
1.2 & 2.0 & 0.36 & 24.22 & 30.16 & 61.80 \\
1.2 & 2.0 & 0.24 & 16.14 & 24.16 & $41.06^{\mathrm{c}}$ \\
1.2 & 2.0 & 0.24 & 13.82 & 20.32 & $33.74^{\mathrm{d}}$ \\
\hline
\end{tabular}

${ }^{a}$ As determined by spectrophotometrically following the disappearance of $\mathrm{Cr}(\mathrm{VI})$ at $359 \mathrm{~nm}$; the error quoted in $k$ values is the $95 \%$ confidence limit of 'Student $t$ test'. ${ }^{b}$ Estimated from pseudo first order plots over $80 \%$ reaction. Solvent Composition $=50 \% \mathrm{AcOH}-50 \% \mathrm{H}_{2} \mathrm{O}(\mathrm{v} / \mathrm{v}){ }^{\mathrm{C}}$ Contained $0.001 \mathrm{~mol}$ $\mathrm{dm}^{-3}$ acrylonitrile. ${ }^{d}$ In the presence of $0.003 \mathrm{~mol} \mathrm{dm}^{-3} \mathrm{Mn}(\mathrm{II})$

\section{Kinetic isotope effect}

To ascertain the importance of the cleavage of the $\alpha-\mathrm{C}-\mathrm{H}$ bond in the rate-determining step, oxidation of $\alpha$-deuterio mandelic acid (DMA) was studied. Results showed the presence of a substantial primary kinetic isotope effect (Table 2). 
Table 2. Kinetic isotope effect on the oxidation of mandelic acid by TriPAFC

\begin{tabular}{ccccc}
\hline \multirow{2}{*}{ Substrate } & \multicolumn{4}{c}{$10^{5} \times k_{l}, \mathrm{~s}^{-1}$} \\
\cline { 2 - 5 } & $298 \mathrm{~K}$ & $303 \mathrm{~K}$ & $308 \mathrm{~K}$ & $313 \mathrm{~K}$ \\
\hline MA & 32.16 & 41.18 & 57.24 & 78.88 \\
DMA & 6.05 & 7.43 & 9.96 & 13.32 \\
$k_{H} / k_{D}$ & 5.34 & 5.54 & 5.75 & 5.92 \\
\hline
\end{tabular}

Solvent composition $=50 \% \mathrm{AcOH}-50 \% \mathrm{H}_{2} \mathrm{O}(\mathrm{v} / \mathrm{v}) 10^{2}[\mathrm{MA}]=2.0 \mathrm{~mol} \mathrm{dm}^{-3} ; 10^{3}[$ TriPAFC] $=1.2 \mathrm{~mol}$ $\mathrm{dm}^{-3} ; 10\left[\mathrm{H}^{+}\right]=2.4 \mathrm{~mol} \mathrm{dm}^{-3}$

\section{Effect of solvent polarity on reaction rate}

The oxidation of $\alpha$-hydroxy acid has been studied in the binary mixture of acetic acid and water as the solvent medium. For the oxidation of all hydroxy acids, the reaction rate increased remarkably with the increase in the proportion of acetic acid in the solvent medium. These results are presented in Table 3.

The effect from solvent composition on the reaction rate was studied by varying the concentration of acetic acid from $30 \%$ to $70 \%$. The pseudo-first-order rate constants were estimated for the oxidation of hydroxy acids, with TriPAFC in the presence of perchloric acid at a constant ionic strength. The reaction rate is increases markedly with the increase in the proportion of acetic acid in the medium (Table 3). When the acid content increases in the medium, the acidity of the medium is increased whereas the dielectric constant of the medium is decreased. These two effects cause the rate of the oxidation to increase markedly. The enhancement of the reaction rate with an increase in the amount of acetic acid generally may be attributed to two factors, viz, (i) the increase in acidity occurring at constant $\left[\mathrm{H}^{+}\right]$, and (ii) the decrease in the dielectric constant with an increase in the acetic acid content.

The plot of $\log k_{l}$ versus 1/D (dielectric constant) is linear with positive slope suggesting the presence of either dipole-dipole or ion-dipole type of interaction between the oxidant and the substrate ${ }^{24,25}$ (Figure 2). Plot of $\log k_{l}$ versus $(\mathrm{D}-1) /(2 \mathrm{D}+1)$ is a curvature indicating the absence of dipole - dipole interaction in the rate determining step. Positive slope of $\log k_{l}$ versus $1 / \mathrm{D}$ plot indicates that the reaction involves a cation-dipole type of interaction in the rate determining step.

Amis (1967) holds the view that in an ion-dipole reaction involving a positive ionic reactant, the rate would decrease with increasing dielectric constant of the medium and if the reactant were to be a negatively charged ion, the rate would increase with the increasing dielectric constant. In this case there is a possibility of a positive ionic reactant, as the rate decreases with the increasing dielectric constant of the medium ${ }^{26}$. Due to the polar nature of the solvent, transition state is stabilized, i.e., the polar solvent molecules surround the transition state and result in less disproportion.

Table 3. Effect of varying solvent polarity on the rate of reaction at $303 \mathrm{~K}$

\begin{tabular}{cccccc}
\hline \%Acetic acid- & Dielectric & \multirow{2}{*}{$1 / \mathrm{D}$} & \multicolumn{3}{c}{$10^{5} k_{l,} \mathrm{~s}^{-1}$} \\
\cline { 4 - 6 } Water (v/v) & constant & & GA & LA & MA \\
\hline $30-70$ & 72.0 & 0.0138 & 12.52 & 18.10 & 31.58 \\
$40-60$ & 63.3 & 0.0158 & 14.44 & 21.56 & 36.60 \\
$50-50$ & 56.0 & 0.0178 & 16.32 & 24.22 & 41.18 \\
$60-40$ & 45.5 & 0.0219 & 20.30 & 32.00 & 53.08 \\
$70-30$ & 38.5 & 0.0259 & 26.12 & 40.36 & 66.72 \\
\hline
\end{tabular}

$10^{2}[\mathrm{HA}]=2.0 \mathrm{~mol} \mathrm{dm} ; 10^{3}[\mathrm{TriPAFC}]=1.2 \mathrm{~mol} \mathrm{dm}^{-3} ; 10\left[\mathrm{H}^{+}\right]=2.4 \mathrm{~mol} \mathrm{dm}^{-3}$ 


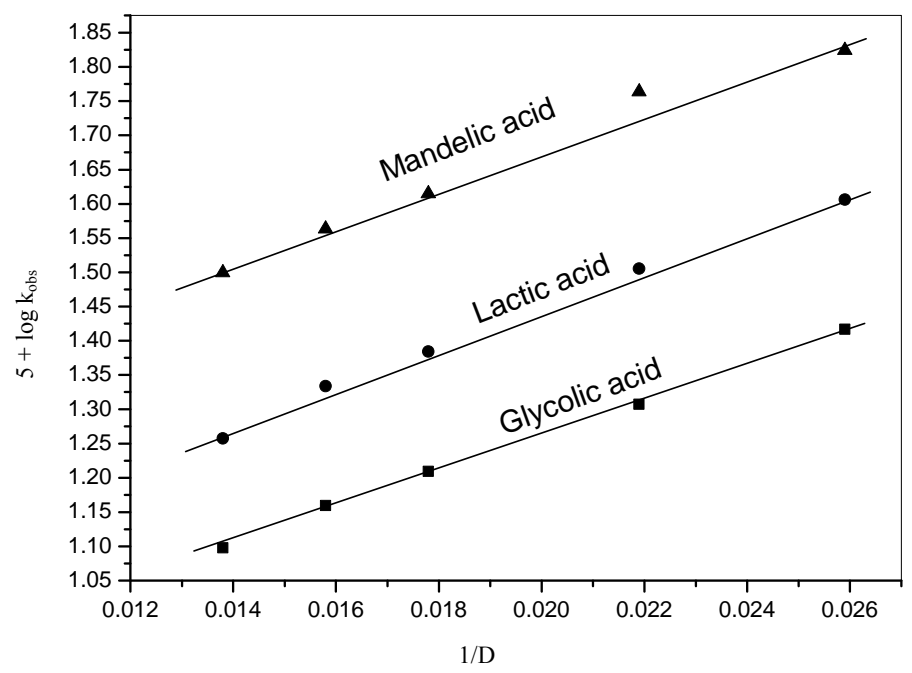

Figure 2. Plot of 1 / D against $\log k_{o b s}$ showing effect of solvent polarity

\section{Thermodynamic parameters}

The kinetics of oxidation of hydroxy acids was studied at four different temperatures viz., 298, 303, 308 and $313 \mathrm{~K}$. The second order rate constants were calculated (Table 4). The Arrhenius plot of $\log k_{2}$ versus $1 / \mathrm{T}$ is found to be linear. The enthalpy of activation, entropy of activation and free energy of activation were calculated from $k_{2}$ at 298, 303, 308 and $313 \mathrm{~K}$ using the Eyring relationship by the method of least square and presented in Table 4. The entropy of activation is negative for hydroxy acids.

Table 4. Activation parameters and second order rate constants for the oxidation of hydroxy acids by TriPAFC in aqueous acetic acid medium

\begin{tabular}{|c|c|c|c|c|c|c|c|c|}
\hline \multirow{2}{*}{ Substrate } & \multicolumn{4}{|c|}{$10^{3} k_{2}, \mathrm{dm}^{3} \mathrm{~mol}^{-1} \mathrm{~s}^{-1}$} & \multirow{2}{*}{$\begin{array}{c}\mathrm{E}_{a} \\
\mathrm{kJmol}^{-1}\end{array}$} & \multirow{2}{*}{$\begin{array}{c}\Delta \mathrm{H}^{\#} \\
\mathrm{kJmol}^{-1}\end{array}$} & \multirow{2}{*}{$\begin{array}{c}-\Delta \mathrm{S}^{\#} \mathrm{JK}^{-1} \\
\mathrm{~mol}^{-1}\end{array}$} & \multirow{2}{*}{$\begin{array}{c}\Delta \mathrm{G}^{\#} \mathrm{kJmol}^{-1} \text {, } \\
\text { at } 303 \mathrm{~K}\end{array}$} \\
\hline & $298 \mathrm{~K}$ & $303 \mathrm{~K}$ & $308 \mathrm{~K}$ & $313 \mathrm{~K}$ & & & & \\
\hline$\overline{\text { GA }}$ & 6.08 & 8.16 & 11.21 & 15.22 & 47.60 & 44.35 & 138.64 & 86.35 \\
\hline LA & 9.04 & 12.11 & 15.80 & 20.45 & 42. & 39.44 & 15 & 85.27 \\
\hline MA & 16.08 & 20.59 & 28.62 & 39.44 & 46.72 & 44.23 & 131.25 & 84.00 \\
\hline
\end{tabular}

Solvent Composition $=50 \% \mathrm{AcOH}-50 \% \mathrm{H}_{2} \mathrm{O}(\mathrm{v} / \mathrm{v}) 10^{2}[\mathrm{HA}]=2.0 \mathrm{~mol} \mathrm{dm^{-3 }} ; 10^{3}[$ TriPAFC] $=1.2$

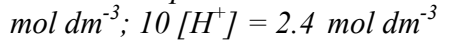

\section{Isokinetic relationship}

The reaction is neither isoenthalpic nor isoentropic but complies with the compensation law also known as the isokinetic relationship.

$$
\Delta \mathrm{H}^{\#}=\Delta \mathrm{H}^{\mathrm{o}}+\beta \Delta \mathrm{S}^{\#}
$$

The isokinetic temperature $\beta$ is the temperature at which all the compounds of the series react equally fast. Also, at the isokinetic temperature, the variation of substituent has no influence on the free energy of activation. Exner ${ }^{27}$ suggested a method of testing the validity of isokinetic relationship. The isokinetic relationship is tested by plotting the logarithms of rate constants at two different temperatures $\left(\mathrm{T}_{2}>\mathrm{T}_{1}\right)$ against each other according to Eq (4).

$$
\log k\left(\text { at } \mathrm{T}_{2}\right)=\mathrm{a}+\mathrm{b} \log k\left(\text { at } \mathrm{T}_{1}\right)
$$


The linear relationship in Exner plots ${ }^{28,29}$ at $4+\log k_{2}(303 \mathrm{~K})$ and $4+\log k_{2}(308 \mathrm{~K})$ observed in the present study imply the validity of the isokinetic relationship. Isokinetic temperature obtained is $418 \pm 12 \mathrm{~K}$. The linear isokinetic correlation implies that GA, LA and MA are oxidized by the same mechanism and the changes in the rate are governed by the changes in both the enthalpy and entropy of activation ${ }^{30}$.

\section{Mechanism of oxidation}

From the product analysis, DNP was confirmed. Hence, it shows that under the experimental conditions employed in the present study, hydroxy acids were oxidized to the corresponding oxo acids. Based on the above kinetic observations the following mechanism is proposed for the reaction. Absence of any effect of added acrylonitrile on the reaction discounts the possibility of a one-electron oxidation, leading to the formation of free radicals. The presence of a substantial kinetic isotope effect in the oxidation of DMA confirms the cleavage of the $\alpha-C-H$ bond in the rate-determining step. Therefore, a hydride-ion transfer in the rate determining step is suggested. Positive slope of $\log k_{1}$ versus $1 / \mathrm{D}$ plot indicates that the reaction involves a cation-dipole type of interaction in the rate determining step. The negative entropy of activation in conjunction with other experimental data supports the mechanism outlined in (Scheme 1).
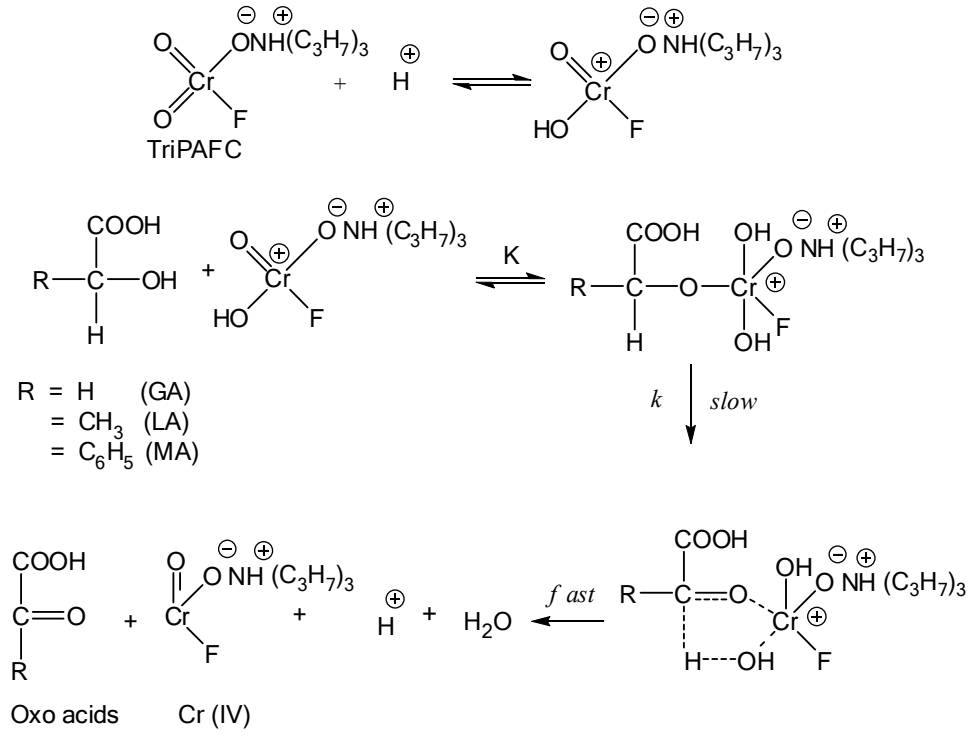

Scheme 1. Mechanism of oxidation of hydroxy acids by TriPAFC

\section{Conclusion}

The kinetics of oxidation of hydroxy acids has been investigated in aqueous acetic acid medium in the presence of perchloric acid by spectrophotometrically at $303 \mathrm{~K}$. The oxidation of hydroxy acids by TriPAFC is first order each with respect to the hydroxy acids, TriPAFC and hydrogen ion. The oxidation is catalysed by perchloric acid. The lowering of dielectric constant of reaction medium increases the reaction rate significantly. The reaction does not show the polymerization, which indicates the absence of free radical intermediate in the oxidation. The order of reactivity is GA $<\mathrm{LA}<\mathrm{MA}$. The reaction rate is higher in LA than in GA due to the inductive effect. Enhanced reactivity in MA may be due to the stabilization of the intermediate formed through resonance. 


\section{References}

1. Patel S and Mishra B K, Tetrahedron, 2007, 63(21), 4367-4406;

DOI:10.1016/j.tet.2007.02.073

2. Viamajala S, Peyton B M, Sani R K, Apel WA and Petersen J N, Biotechnol Prog., 2004, 20(1), 87-95; DOI:10.1021/bp034131q

3. Mansoor S S and Shafi S S, Z Phys Chem., 2011, 225(2), 249-263;

DOI:10.1524/zpch.2011.0044

4. Mansoor S S and Shafi S S, Arab J Chem., 2014, 7(2), 171-176;

DOI:10.1016/j.arabjc.2010.10.020

5. Ghammamy S and Dastpeyman S, J Chin Chem Soc., 2008, 55(1), 229-232;

DOI:10.1002/jccs.200800034

6. Alhaji N M I, Shajahan A and Ayyadurai G K, Chem Sci Trans., 2013, 2(2), 429434; DOI:10.7598/cst2013.376

7. Koohestani B, Javanshir Z, Ghammamy S, Mehrani K, Afrand H and Saghatforoush L, J Mex Chem Soc., 2008, 52, 116-119.

8. Mansoor SS and Shafi SS, React Kinet Mech Catal., 2010, 100(1), 21-30; DOI:10.1007/s11144-010-0148-4

9. Ghammamy S and Hashemzadeh A, Bull Korean Chem Soc., 2004, 25(8), $1277-$ 1279; DOI:10.5012/bkcs.2004.25.8.1277

10. Mansoor S S, Malik V S, Aswin K, Logaiya K and Hussain A M, J Saudi Chem Soc., 2012; DOI:10.1016/j.jscs.2012.09.013

11. Swami P, Yajurvedi D, Mishra P and Sharma P K, Int J Chem Kinet., 2010, 42(1), 50-55; DOI:10.1002/kin.20466

12. Ahmed S Z, Shafi S S and Mansoor S S, Asian J Chem., 2013, 25(2), 921-925; DOI:10.14233/ajchem.2013.13142

13. Kumbhat V, Sharma P K and Banerji K K, Int J Chem Kinet, 2000, 34(4), 248-254; DOI:10.1002/kin.10036

14. Sen Gupta K K, Pal B and Sen P K, Int J Chem Kinet., 1999, 31(12), 873-882; DOI:10.1002/(SICI)1097-4601(1999)31:12<873::AID-KIN6>3.0.CO;2-Z

15. Kothari A, Kothari S, Banerji K K, Indian J Chem., 2000, 39A, 734-739.

16. Nalwaya N, Jain and Hiran B L, Oxidn Commun., 2003, 26, 561-566.

17. Vyas N, Daiya A, Choudhary A, Sharma M and Sharma V, Eur Chem Bull., 2013, 2(11), 859-865

18. Garg D and Kothari S, J Chem Sci., 2004, 26(6), 333-338; DOI:10.1007/BF02711434

19. Malani N, Baghmar M, Swami P and Sharma P K, Prog Reac Kinet Mech., 2008, 33(4), 392-404; DOI:10.3184/146867808X379300

20. Karunakaran C and Suesh S, J Phys Org Chem., 2004, 17(1), 88-93; DOI:10.1002/poc.699

21. Khan Z, Yousf Dar M and Babe P S S, Indian J Chem., 2004, 42A, 1060-1065.

22. Sharma V, Sharma P K, Banerji K K, J Indian Chem Soc., 1997, 74, 607-609.

23. Sharma V, Sharma P K and Banerji K K, J Chem Research (S), 1996, 290-291.

24. Scatchard G J, Chem Phys., 1932, 10(2-3), 229-233; DOI:10.1016/03010104(75)87038-8

25. Scatchard G J, Chem Phys., 1939, 7, 657.

26. Amis E S, Solvent Effects on Reaction Rates and Mechanisms. Academic Press, New York, 1967, 42. 
27. Bhuvaseshwari D S and Elango K P, Int J Chem Kinet., 2007, 39(12), 657-663; DOI:10.1002/kin.20275

28. Exner O, Nature, 1964, 201, 488-490; DOI:10.1038/201488b0

29. Exner O, Streitwiser J R and Talt R W, Progress in Physical Organic Chemistry, John Wiley, New York, 1973, 41.

30. Leffler J F and Grunwald E, Rates and Equilibrium of Organic Reactions, Wiley, New York, 1963. 